\title{
Acid-sensing channels in human bladder: expression, function and alterations during bladder pain syndrome
}

Verónica Sánchez-Freire ${ }^{1 \uparrow \mathbf{A}}$, Maxime G. Blanchard ${ }^{2 \mathrm{~A}}$, Fiona C. Burkhard ${ }^{3}$, Thomas M. Kessler ${ }^{3 \S}$, Stephan Kellenberger ${ }^{2}$, and Katia Monastyrskaya ${ }^{1^{*}}$

${ }^{1}$ Department of Cell Biology, Institute of Anatomy, University of Bern, 3000 Bern 9, Switzerland

2 Department of Pharmacology and Toxicology, University of Lausanne, 1005 Lausanne, Switzerland

${ }^{3}$ Department of Urology, University Hospital, 3010 Bern, Switzerland

" Present address: Stanford University School of Medicine, 300 Pasteur Drive, Stanford CA, USA

$\S$ Present address: Neuro-Urology, Spinal Cord Injury Center, University Hospital Balgrist, 8008 Zürich, Switzerland

A V. Sanchez-Freire and M.G. Blanchard have equally contributed to this work

\section{* Corresponding author:}

Katia Monastyrskaya,

Department of Cell Biology,

Institute of Anatomy, University of Bern,

3000 Bern 9, Switzerland.

Tel: +413163130 86;

Fax: + 41316313607 ;

Email: monastyk@ana.unibe.ch

Word count: abstract 247, text 2909

Keywords: pain, bladder, acid-sensing channels, gene expression, mRNA, urothelium 


\section{ABSTRACT}

Purpose: To examine the possible role of $\mathrm{H}^{+}$-activated acid-sensing ion channels (ASICs) in pain perception we characterized their expression in bladder dome biopsies of Bladder Pain Syndrome (BPS) patients and controls, in cultured human urothelium and in urothelial TEU-2 cells.

Materials and Methods: Cold cut biopsies from the bladder dome were obtained in 8 asymptomatic controls and 28 patients with symptoms of BPS. ASIC expression was analyzed by QPCR and immunofluorescence. The channel function was measured by electrophysiology.

Results: ASIC1a, ASIC2a and ASIC3 mRNAs were detected in human bladder. Similar amounts of ASIC1a and -3 were detected in detrusor smooth muscle, whereas in urothelium ASIC3 levels were higher than -1a. ASIC2a mRNA levels were lower than either -1a or -3 in both layers. ASIC currents were measured in TEU-2 cells and in primary cultures of human urothelium, and ASIC expression was confirmed by QPCR. Differentiation of TEU-2 cells caused an up-regulation of ASIC2a and ASIC3, and a down-regulation of ASIC1a mRNAs. BPS patients showed an up-regulation of ASIC2a and -3 mRNA, whereas ASIC1a remained unchanged. In contrast, the mRNA levels of TRPV1 were down-regulated during BPS. All differences were statistically significant $(\mathrm{p}<0.05)$

Conclusions: Several different ASIC subunits are expressed in human bladder and TEU-2 cells, where their levels are regulated during urothelial differentiation. An up-regulation of ASIC2a and -3 in BPS suggests their involvement in increased pain and hyperalgesia. A down-regulation of TRPV1 mRNA levels might indicate a different regulatory mechanism, controlling its expression in human bladder. 


\section{INTRODUCTION}

Bladder pain syndrome (BPS)/ interstitial cystitis (IC) is a clinical syndrome of pelvic pain, urgency and/or frequency without an identifiable cause, characterized by chronic inflammation. Tissue acidosis is a hallmark of inflammation and is thought to contribute to pain ${ }^{1}$. Tissue acidosis is detected by channels which are gated or modulated by protons and capable of acid nociception. Acid-sensing ion channels (ASICs) are voltage-insensitive cation channels activated by extracellular protons. Functional ASICs are formed by homo- or heterotrimeric assembly of ASIC subunits $1 \mathrm{a}, 1 \mathrm{~b}, 2 \mathrm{a}, 2 \mathrm{~b}$ and/or $3^{2}$. Expression of ASICs in nociceptive neurons and their activation by protons suggest a function as pain receptors, and several animal models provide an evidence for that ${ }^{3,4}$. Most ASICs are transiently activated by $\mathrm{pH}$ changes in the physiological range, with $\mathrm{pH}$ of half-maximal activation values varying between 6.8 and 4.5, and activation thresholds as high as $\mathrm{pH}$ 7.0. Some ASIC isoforms display in addition to the transient also a small sustained component that lasts as long as the $\mathrm{pH}$ remains acidic ${ }^{5}$. ASICs are present in dorsal root ganglion neurons ${ }^{6}$, and in the central nervous system ${ }^{7}$, as well as in vascular smooth muscle ${ }^{8}$. The presence and function of ASICs in the bladder has been investigated in animal models. In mice, ASIC1 is the dominant ASIC subunit expressed in urothelium, whereas both ASIC1 and ASIC2 are expressed in bladder smooth muscle. ASIC3 expression is less abundant, and this subunit has been localized to the sub-epithelial region ${ }^{9}$. Using QPCR, the presence of ASIC1, -2 and -3 was confirmed in rat DRG, detrusor and mucosal tissues ${ }^{10}$.

Although ASICs have been implicated in bladder nociception, human data are scarce. BPS patients often report worsening of their symptoms and increased pain perception following ingestion of products which acidify urine ${ }^{11,12}$. A recent study addressed the role of ASICs in experimentallyinduced cystitis in rats treated with cyclophosphamide (CYP) ${ }^{13}$, providing the first evidence for ASIC up-regulation in the bladder during inflammation. CYP-induced cystitis is a widely accepted animal model of this condition. However it is important to assess the disease-mediated changes of ASIC expression in humans with chronic BPS. We studied the expression levels of three ASIC transcripts (ASIC1a, ASIC2a, and ASIC3) in the layers of healthy human bladder. We functionally characterized these channels in human primary UE cultures and the immortalized urothelial cell line TEU-2 ${ }^{14}$. We investigated the presence of ASICs, and measured ASIC-mediated currents as well as differentiation-induced changes of ASIC gene expression.

The transient receptor potential vanilloid 1 (TRPV1) channel, which is activated by chemical, mechanical and thermal stimuli including noxious heat $\left(\mathrm{T}>43^{\circ} \mathrm{C}\right)$, acid $(\mathrm{pH} \leq 6)$ and capsaicin, is a putative acid sensor in the bladder. In bladder dysfunction TRPV1 has been shown to regulate the 
frequency of bladder reflex contractions in chronically inflamed rat bladders ${ }^{15}$ and be essential for cystitis-induced mechanical hyper-reactivity, though not involved in the cystitis development ${ }^{16}$. Although different functional TRPs have been detected in cultured rodent urothelial cells ${ }^{17}$, and TRPV1 immunoreactivity has also been reported in the human detrusor ${ }^{18}$, the presence of functional TRPV1 in urothelial cells might be species-specific ${ }^{19,20}$. In order to investigate the possible role of both types of channels in bladder pain, we examined the expression levels of the 3 most important ASIC subunits and TRPV1 in BPS patients, and compared them to the controls.

\section{MATERIALS AND METHODS}

\section{Subjects}

Permission to conduct this study was obtained from the Ethics Committee of the Canton of Bern (KEK 146/05), and all subjects gave written informed consent. Patient selection and evaluation was done as described previously ${ }^{21}$. Patients were divided in 2 groups:

1) Controls - asymptomatic patients undergoing cystoscopy for other reasons (e.g. stent placement for stone disease, microhematuria evaluation).

2) BPS - patients with pain ( $>3$ months) considered to be located in the bladder and/or frequency, urgency and nocturia.

Cold cut biopsies from the bladder dome were collected from 8 controls and 28 BPS patients. The biopsies were preserved in RNAlater (Qiagen) and stored at $-70^{\circ} \mathrm{C}$ until RNA isolation. For morphological studies, samples from the dome were obtained from 4 patients ( 3 female and 1 male, mean age 65 years, range 52-74) undergoing radical cystectomy for bladder cancer, who had no lower urinary tract symptoms aside from hematuria.

\section{Cell culture}

Primary cultures of bladder smooth muscle and urothelium were established and maintained as described previously ${ }^{21}$. The immortalized human urothelial cell line (TEU-2) ${ }^{22}$ was maintained in serum-free EpiLife Medium supplemented with Human Keratinocyte Growth supplement (HKGS) and antibiotics (Cascade Biologics). Differentiation of TEU-2 cells was achieved by addition of serum and $\mathrm{Ca}^{2+}$ as previously described ${ }^{23}$.

\section{Total RNA isolation, reverse transcription and real-time PCR analysis of $m R N A$ expression}

Total RNA isolated as described previously ${ }^{21}$. In order to separate bladder urothelium from the underlying stroma, post-operative tissue was treated with $5 \mathrm{mg} / \mathrm{ml}$ of dispase II overnight at $4^{\circ} \mathrm{C}$. The reverse transcription reactions were carried out using the High Capacity cDNA Reverse Transcription 
Kit (Applied Biosystems) with random hexamer primers. TRPV1 TaqMan primer (Hs00218912_m1) for QPCR was from Applied Biosystems. The ASIC primers for SYBR-Green QPCR were designed by using PrimerBLAST software and synthesized by Microsynth (Switzerland). The following primer pairs were used (all based on human sequences): 28S rRNA (endogenous control) forward 5' TCTGACTTAGAGGCGTTCAGT CATAAT 3', reverse GTTGTTGCCATGGTAATCCTGCTCAGT3'; ASIC1a forward 5' ACC TGTATCATGCTGGGGAG 3', reverse 5' TGCTTTTCATCTGCCATCTG 3'; ASIC2a forward 5' CCACATCTTCGTGTATGGGC 3', reverse 5' CCTCTCAGAGCTCTCCACCA 3'; ASIC3 forward 5' AGAGGGTGCGCTACTACA GG 3', reverse 5' TTGATGTTGCACAGGGTGAC 3'; TRPV1+1b forward 5'GGACTCGGTGGGCAACACGG 3', reverse 5' CAGCTTCAGCGTCGGGTGCAG 3'; TRPV1 long isoform (exon 7-specific) forward 5' AGCGGGAGATCCAGGAGCCC 3', reverse 5' AGGGGTCTCGCTGCTGCTGT 3'. SYBR-Green quantitative real-time PCR (QPCR) was carried out in triplicates using 7900HT Fast Real-time PCR System (Applied Biosystems). The Ct values obtained after the real time-QPCR were normalized to the $18 \mathrm{~S}$ housekeeping gene when performing TaqMan QPCR and to the 28S housekeeping gene when performing SYBR-Green QPCR.

\section{Tissue sections and immunofluorescence labeling}

Ultracryomicrotomy and immunohistochemistry were performed as previously described ${ }^{21}$. Rabbit polyclonal anti-ASIC1 antibodies ${ }^{24}$, recognizing the C-terminus common to ASIC1a and $-1 \mathrm{~b}$ were a kind gift from J.A.Wemmie, mouse monoclonal anti-SM $\alpha$-actin antibody IA4 was from Sigma. Tissue sections were examined at Axiovert $200 \mathrm{M}$ microscope with laser scanning module LSM 510 META (Zeiss).

\section{Electrophysiology}

Electrophysiological measurements and analyses were carried out with an EPC10 patch-clamp amplifier (HEKA Electronics, Lambrecht, Germany) HEKA's Patchmaster and Fitmaster software. Experiments were carried out with the whole-cell patch-clamp technique at a holding potential of -60 $\mathrm{mV}$. Fast solution exchange ( $\sim 100 \mathrm{~ms})$ was achieved using the cF-8VS computer-controlled electro valve assembly and the MPRE8 perfusion system (Cell MicroControls, Norfolk, VA, USA). Pipettes were pulled from borosilicate glass (World Precision Instruments, Stevenage, UK) and had resistance between 2 and $4 \mathrm{M} \Omega$ when filled with the pipette solution. Pipette solutions contained (in $\mathrm{mM}$ ) 90 $\mathrm{CsOH}, 90$ Gluconic Acid, $10 \mathrm{NaCl}, 10 \mathrm{KCl}, 1 \mathrm{MgCl}_{2}$, 60 Hepes, 10 EGTA; pH adjusted to 7.3 with CsOH. Extracellular solutions contained (in mM) $140 \mathrm{NaCl}, 4 \mathrm{KCl}, 2 \mathrm{CaCl}_{2}, 1 \mathrm{MgCl}_{2}, 10 \mathrm{HEPES}, 10$ MES, 10 glucose; $\mathrm{pH}$ adjusted to the desired value using $\mathrm{NaOH}$ or $\mathrm{HCl}$. Amiloride was added from 5 
$\mathrm{mM}$ stock solution in water. Chemicals were obtained from Acros Organics (Geel, Belgium), Applichem (Darmstadt, Germany), and Sigma or Fluka (Buchs, Switzerland). Data are presented as mean \pm SEM.

\section{Statistical and data analysis}

In patients' studies the normality was defined with Kolmogorov-Smirnov and Shapiro-Wilk tests $(\mathrm{p}<$ 0.05). Statistically significant differences were determined with a Mann Whitney U test with an $\alpha$ set to 0.05 for genes not displaying a normal distribution, and with a two-tailed Student's $t$-test, preceded by a Levene's test, with an $\alpha$ set to 0.05 for genes with a normal distribution. The results of cell assays were analyzed using one-way ANOVA followed by Tukey's multiple comparison test. All studies were carried out with the SPSS program (version 17.0).

ASIC pH dependence of activation curves was fitted with the following Hill equation: $\mathrm{I}=\operatorname{Imax} /\left(1+\left(10^{-\mathrm{pH} 0.5} / 10^{-\mathrm{pH}}\right)^{\mathrm{nH}}\right)$ where Imax is the maximal current, $\mathrm{pH} 0.5$ is the $\mathrm{pH}$ of half maximal activation and $\mathrm{nH}$ he Hill number. ASIC inactivation kinetics were fitted with the following equation: $I=I_{0} * \exp \left(-t / \tau_{i}\right)$ where $I_{0}$ is the peak current, $t$ the time and $\tau_{i}$ the time constant of inactivation.

\section{RESULTS}

Expression of ASIC mRNAs in different layers of the human bladder and in cultured smooth muscle and urothelium cells

In bladder samples obtained after cystectomies from patients without lower urinary tract symptoms, the urothelium layer was separated from the underlying stroma by enzymatic digestion followed by RNA isolation. The purity of urothelial samples was confirmed by QPCR using urothelium (UE)- and smooth muscle (SM)-specific markers as described previously ${ }^{21}$. Uroplakin UPII was only detected in urothelium, whereas transgelin SM22 was only amplified in the stroma samples (Fig. 1). ASIC1a, -2a and -3 mRNAs were detected in urothelium and sub-urothelial stroma (Fig. 2A). In stroma there were no differences in the expression levels of ASIC3 and ASIC1a, whereas mRNA levels of ASIC2a were significantly lower $(\mathrm{p}<0.05)$ (Table 1$)$. ASIC1a was significantly more abundant in the stroma than in the isolated urothelium (Fig. 2A).

All studied ASIC types were detected in primary cultures of UE and SM, however with a lower relative abundance than in the total bladder samples (Table 1). In contrast to bladder tissue, the differences in expression levels of ASICs between UE- and SM-primary cultures were not statistically significant (Fig. 2B). 
Immunofluorescence detection of ASIC1 in healthy human bladder

Using immunofluorescence labeling of ultrathin cryosections, we observed a modest labeling of the urothelium cell layer with anti-ASIC1 antibodies (Fig. 2, upper panels). In contrast, the detrusor smooth muscle showed a strong staining, which fully co-localized with SM $\alpha$-actin-specific monoclonal antibody (Fig. 3, lower panels). We restricted our analysis of ASIC protein expression to ASIC1, because the commercially available antibodies for ASIC2 and ASIC3 that we had tested did not show specific staining when used in immunofluorescence labeling of dorsal root ganglion neurons of ASIC2 and -3 knockout mice, respectively (data not shown).

ASIC expression and function in the TEU-2 urothelial cell line and in cultured human UE cells

During differentiation of TEU-2 cells we observed a re-localization of the tight junction (TJ) protein occludin from the cytoplasm to the plasma membrane of the apical cells (Fig. 4A), and a concomitant increase in transepithelial electrical resistance, indicating the formation of a tight epithelium (not shown). We readily detected ASIC1a, and -3 by QPCR in TEU-2 monolayers, whereas the levels of ASIC2a were very low (Table 1). ASIC1a mRNA was significantly more abundant $(\mathrm{p}<0.05)$ than ASIC3 or -2a in undifferentiated TEU-2 (Table 1). We measured mRNA levels of ASICs in TEU-2 cells after 24, 48 and $72 \mathrm{~h}$ in differentiation medium, and observed a significant $(\mathrm{p}<0.05)$ upregulation of ASIC2a and ASIC3 mRNA (Fig. 4B). In contrast, the levels of ASIC1a were reduced ( $p<$ 0.05 ) during the differentiation process (Fig.4B). Following $72 \mathrm{~h}$ differentiation, the mRNA levels of ASIC3 became significantly $(\mathrm{p}<0.05)$ higher than those of ASICla, whereas the relative abundance of ASIC2a remained the lowest of the studied transcripts (Table 1).

To test for the presence of functional ASICs we carried out whole-cell patch-clamp recordings from undifferentiated TEU-2 cells and from cultured human UE cells (two independent UE preparations). In both cell systems, a short (2.5-5 s) extracellular acidification from $\mathbf{p H} 7.4$ to $\mathrm{pH}$ 6 induced an inward current composed of a fast transient component and sustained component of variable amplitude (Fig.5A and 5B). The ASIC/ENaC blocker amiloride at $200 \mu \mathrm{M}$ reversibly inhibited the transient, but not the sustained inward current (Fig.5A, summarized in Fig. 5D). The pH dependence of the ASIC currents was measured from the peak current amplitude in response to $\mathrm{pH}$ changes from $\mathrm{pH} 7.4$ to different values, as illustrated by representative traces in Fig. 5B. The normalized current amplitude is plotted as a function of the stimulation pH in Fig. 5C. To correct for the current rundown observed with repetitive stimulation, the measured amplitudes were normalized to the amplitudes of $\mathrm{pH} 6.5$ reference responses measured between test stimulations. Fitting of the data to the Hill equation (Material and Methods) yielded a pH of 
half-maximal activation (and Hill number) of $6.56 \pm 0.01(\mathrm{nH}=4.14 \pm 0.36, \mathrm{n}=6)$ and $6.52 \pm 0.03$ $(\mathrm{nH}=3.15 \pm 1.19, \mathrm{n}=10)$ for $\mathrm{TEU}-2$ and $\mathrm{UE}$ cells respectively (Fig 5C), suggesting that this current is likely mediated by ASICs composed of subunits other than ASIC2. The pH6-induced amiloride-sensitive peak current density was $-4.5 \pm 1.0(\mathrm{n}=8)$ and $-1.36 \pm 0.27 \mathrm{pA} / \mathrm{pF}(\mathrm{n}=13)$ in TEU-2 and UE cells, respectively. The pH6-evoked amiloride-sensitive inward currents inactivated with a time constant $\tau_{1}=1.1 \pm 0.1(\mathrm{n}=8)$ and $1.2 \pm 0.2 \mathrm{~s}(\mathrm{n}=8)$ for TEU-2 and UE cells respectively.

Although we detected TRPV1 mRNA in TEU-2 cells using QPCR, perfusion of 1-10 $\mu M$ capsaicin, a potent TRPV1 activator, did not elicit measurable inward currents in undifferentiated TEU-2 cells $(n=9)$ nor in UE cells $(n=14)$ (data not shown), suggesting that the observed low pH-evoked sustained current is not mediated by TRPV1. Using primers specific for TRPV1 exon 7 we were able to differentiate the expression of the full-length capsaicin-sensitive TRPV1 channel and its truncated dominant-negative isoform TRPV1b ${ }^{25}$ in TEU-2 cells. We show that in contrast to bladder tissue, TEU-2 cells express approximately 5-fold excess of TRPV1b (Fig. 6).

\section{Changes of ASICs and TRPV1 mRNA expression levels in BPS patients}

We investigated the mRNA levels of ASICs and TRPV1 in bladder biopsies of 28 patients compared to 8 controls. Using QPCR we show that ASIC2a, and -3 were significantly $(\mathrm{p}<0.05)$ up-regulated in BPS patients compared to controls (Fig. 7A). No differences were found in ASIC1a mRNA levels (Fig. 7A). In contrast, TRPV1 mRNA was significantly $(\mathrm{p}<0.05)$ down-regulated in BPS patients (Fig 7B).

\section{DISCUSSION}

Tissue acidosis is a common feature of inflammatory and ischemic conditions, and there are indications for roles of ASICs and TRPV1 in pain sensation. We investigated the localization of ASIC isoforms in the human urinary bladder using QPCR and for ASIC1 by immunofluorescence. After a careful separation of the urothelium from the underlying tissue, we showed that all 3 investigated types of ASIC mRNA were detectable in both bladder layers, but there were differences in their amount and distribution. We showed that ASIC1a mRNA levels were significantly higher in sub-urothelial stroma than in purified urothelium. These observations were confirmed by immunofluorescence labeling, showing a strong ASIC1 antibody staining of the detrusor and vascular smooth muscle. In the isolated urothelium the mRNA levels of ASIC3 were significantly higher than ASIC1a, and ASIC2a was the least abundant mRNA as judged by QPCR. 
To further characterize ASIC expression and function we used the urothelial cell line TEU-2. ASIC2a and ASIC3 mRNA levels significantly increased, whereas ASIC1a mRNA levels decreased during TEU-2 differentiation. Electrophysiological measurements showed that both the primary cultures of human urothelium and TEU-2 cells express functional ASICs, supporting our gene expression studies. In contrast, perfusion with capsaicin failed to elicit measurable currents, indicating the lack of functional TRPV1 channels in TEU-2 cells and primary UE cultures. Analysis of TRPV1 isoforms revealed a significant excess of the dominant-negative TRPV1b mRNA over the full-length TRPV1. The high abundance of this capsaicin-insensitive isoform ${ }^{25}$ might explain the lack of TRPV1-mediated currents in these cells.

We analyzed the levels of mRNAs encoding ASICs and TRPV1 in the cold-cut biopsies of human BPS patients, and showed a significant up-regulation of ASIC2a and -3, but not ASIC1a, in the BPS compared to the controls. In contrast to ASICs, the mRNA levels of TRPV1 were significantly lower in PBS patients compared to controls. TRPV1 localization has been well studied in bladder ${ }^{18}$, and it has been implicated in generating the high frequency bladder reflex contractions ${ }^{26}$, and mediating the bladder hyperactivity and noxious input induced by cystitis in mice ${ }^{27}$. It is possible that the expression of ASICs and TRPV1 in peripheral tissues is differentially regulated during BPS, accounting for the observed decrease of TRPV1 mRNA levels. Interestingly, a similar down-regulation of TRPV1 has been recently observed in urothelial cancer ${ }^{28}$. The biopsy collection protocol did not allow enough material to estimate the ASIC protein levels in BPS patients, which is a limitation of this study.

Our ASIC data are in a good agreement with a recently published study, examining expression levels of these channels in the bladders of CYP-treated rats, where the acute and chronic administration of CYP increased ASIC2a and -3 mRNA levels up to 6-fold in bladder urothelium, but not in detrusor ${ }^{13}$. Similar to our results, no up-regulation of ASIC1 was detected in rats ${ }^{13}$. In a separate study of an inflammatory muscle injury in mice, ASIC2 and -3 mRNAs were elevated, but ASIC1 remained unchanged $^{29}$. Therefore, an up-regulation of ASIC2a and -3 in BPS, reported here at the mRNA level in the human patients, and previously in animal models, might represent a general adaptive mechanism contributing to the increased pain responses. ASIC3 has been implicated in sensing prolonged acidification, and would therefore be a suitable candidate for the role of acidification sensor in bladder urothelium. Our results demonstrate a differential regulation of ASIC isoforms in the human bladder layers, which might contribute to the pain perception during BPS. 


\section{CONCLUSIONS}

Our study is the first to address the potential involvement of ASICs in BPS in humans. We show that ASICs are present in human bladder urothelium and smooth muscle. There is a significant downregulation of TRPV1, and up-regulation of mRNA levels of ASIC2a and ASIC3 in BPS patients compared to the controls. The up-regulation of ASICs in BPS might contribute to the bladder pain experienced in this condition.

\section{ACKNOWLEDGMENTS}

Human material was kindly provided by the Tumorbank Bern. The Tumorbank Bern is sponsored by the Department of Clinical Research, University of Bern and the Bernese Cancer League. We are grateful to Dr. David J. Klumpp (Northwestern University, Chicago, USA) for providing TEU-2 cell line, Dr Annette Kuhn for help in sample collection, Mrs. Catherine Allemann for the preparation of bladder slices, Mr. H. P. Gaeggeler for collagen preparation, Mr. Daniel Muellener for assistance. We gratefully acknowledge the financial support of the Swiss National Science Foundation (SNF Grant 320000-111778 to KM, SNF Grant 31003A-117717 to SK).

\section{CONFLICT OF INTEREST}

F.C. Burkhard is a past-consultant to Medtronic, T. M. Kessler has acted as consultant for Medtronic and Allergan.

\section{ABBREVIATIONS}

BPS, bladder pain syndrome; ASIC, acid-sensing ion channel; QPCR, quantitative RT-PCR; SM, smooth muscle; UE, urothelium; TJ, tight junctions; UEC or SMC, urothelial/smooth muscle cultures. 


\section{References}

1. Jones, N. G., Slater, R., Cadiou, H., McNaughton, P., and McMahon, S. B.: Acid-induced pain and its modulation in humans. J Neurosci, 24: 10974, 2004.

2. Wemmie, J. A., Price, M. P., and Welsh, M. J.: Acid-sensing ion channels: advances, questions and therapeutic opportunities. Trends Neurosci, 29: 578, 2006.

3. Sluka, K. A., Price, M. P., Breese, N. M., Stucky, C. L., Wemmie, J. A., and Welsh, M. J.: Chronic hyperalgesia induced by repeated acid injections in muscle is abolished by the loss of ASIC3, but not ASIC1. Pain, 106: 229, 2003.

4. Deval, E., Noel, J., Lay, N., Alloui, A., Diochot, S., Friend, V. et al.: ASIC3, a sensor of acidic and primary inflammatory pain. EMBO J, 27: 3047, 2008.

5. Yagi, J., Wenk, H. N., Naves, L. A., and McCleskey, E. W.: Sustained currents through ASIC3 ion channels at the modest $\mathrm{pH}$ changes that occur during myocardial ischemia. Circ Res, 99: 501, 2006.

6. Poirot, O., Berta, T., Decosterd, I., and Kellenberger, S.: Distinct ASIC currents are expressed in rat putative nociceptors and are modulated by nerve injury. J Physiol, 576: 215, 2006.

7. Alvarez, d. 1. R., Krueger, S. R., Kolar, A., Shao, D., Fitzsimonds, R. M., and Canessa, C. M.: Distribution, subcellular localization and ontogeny of ASIC1 in the mammalian central nervous system. J Physiol, 546: 77, 2003.

8. Chung, W. S., Farley, J. M., Swenson, A., Barnard, J. M., Hamilton, G., Chiposi, R. et al.: Extracellular acidosis activates ASIC-like channels in freshly isolated cerebral artery smooth muscle cells. Am J Physiol Cell Physiol, 298: C1198, 2010.

9. Kobayashi, H., Yoshiyama, M., Zakoji, H., Takeda, M., and Araki, I.: Sex differences in the expression profile of acid-sensing ion channels in the mouse urinary bladder: a possible involvement in irritative bladder symptoms. BJU Int, 2009.

10. Sadananda, P., Shang, F., Liu, L., Mansfield, K. J., and Burcher, E.: Release of ATP from rat urinary bladder mucosa: role of acid, vanilloids and stretch. Br J Pharmacol, 158: 1655, 2009.

11. Marinkovic, S. P., Moldwin, R., Gillen, L. M., and Stanton, S. L.: The management of interstitial cystitis or painful bladder syndrome in women. BMJ, 339: b2707, 2009.

12. Moldwin, R. M., Evans, R. J., Stanford, E. J., and Rosenberg, M. T.: Rational approaches to the treatment of patients with interstitial cystitis. Urology, 69: 73, 2007.

13. Corrow, K., Girard, B. M., and Vizzard, M. A.: Expression and Response of Acid-Sensing Ion Channels (ASICs) in Urinary Bladder to Cyclophosphamide (CYP)-Induced Cystitis. Am J Physiol Renal Physiol, 2010. 
14. Rickard, A., Dorokhov, N., Ryerse, J., Klumpp, D. J., and McHowat, J.: Characterization of tight junction proteins in cultured human urothelial cells. In Vitro Cell Dev Biol Anim, 44: 261, 2008.

15. Avelino, A. and Cruz, F.: TRPV1 (vanilloid receptor) in the urinary tract: expression, function and clinical applications. Naunyn Schmiedebergs Arch Pharmacol, 373: 287, 2006.

16. Wang, Z. Y., Wang, P., Merriam, F. V., and Bjorling, D. E.: Lack of TRPV1 inhibits cystitisinduced increased mechanical sensitivity in mice. Pain, 139: 158, 2008.

17. Yu, W., Hill, W. G., Apodaca, G., and Zeidel, M. L.: Expression and Distribution of Transient Receptor Potential (TRP) Channels in Bladder Epithelium. Am J Physiol Renal Physiol, 2010.

18. Everaerts, W., Gevaert, T., Nilius, B., and De, R. D.: On the origin of bladder sensing: $\operatorname{Tr}(i) p s$ in urology. Neurourol Urodyn, 27: 264, 2008.

19. Everaerts, W., Vriens, J., Owsianik, G., Appendino, G., Voets, T., De, R. D. et al.: Functional characterization of transient receptor potential channels in mouse urothelial cells. Am $\mathrm{J}$ Physiol Renal Physiol, 298: F692, 2010.

20. Charrua, A., Reguenga, C., Cordeiro, J. M., Correiade-Sa, P., Paule, C., Nagy, I. et al.: Functional transient receptor potential vanilloid 1 is expressed in human urothelial cells. J Urol, 182: 2944, 2009.

21. Sanchez Freire, V., Burkhard, F. C., Kessler, T. M., Kuhn, A., Draeger, A., and Monastyrskaya, K.: MicroRNAs may mediate the down-regulation of neurokinin-1 receptor in chronic bladder pain syndrome. Am J Pathol, 176: 288, 2010.

22. Klumpp, D. J., Weiser, A. C., Sengupta, S., Forrestal, S. G., Batler, R. A., and Schaeffer, A. J.: Uropathogenic Escherichia coli potentiates type 1 pilus-induced apoptosis by suppressing NF-kappaB. Infect Immun, 69: 6689, 2001.

23. Rickard, A., Dorokhov, N., Ryerse, J., Klumpp, D. J., and McHowat, J.: Characterization of tight junction proteins in cultured human urothelial cells. In Vitro Cell Dev Biol Anim, 44: 261, 2008.

24. Wemmie, J. A., Askwith, C. C., Lamani, E., Cassell, M. D., Freeman, J. H., Jr., and Welsh, M. J.: Acid-sensing ion channel 1 is localized in brain regions with high synaptic density and contributes to fear conditioning. J Neurosci, 23: 5496, 2003.

25. Vos, M. H., Neelands, T. R., McDonald, H. A., Choi, W., Kroeger, P. E., Puttfarcken, P. S. et al.: TRPV1b overexpression negatively regulates TRPV1 responsiveness to capsaicin, heat and low pH in HEK293 cells. J Neurochem, 99: 1088, 2006.

26. Charrua, A., Cruz, C. D., Cruz, F., and Avelino, A.: Transient receptor potential vanilloid subfamily 1 is essential for the generation of noxious bladder input and bladder overactivity in cystitis. J Urol, 177: 1537, 2007. 
27. Charrua, A., Cruz, C. D., Narayanan, S., Gharat, L., Gullapalli, S., Cruz, F. et al.: GRC-6211, a new oral specific TRPV1 antagonist, decreases bladder overactivity and noxious bladder input in cystitis animal models. J Urol, 181: 379, 2009.

28. Kalogris, C., Caprodossi, S., Amantini, C., Lambertucci, F., Nabissi, M., Morelli, M. B. et al.: Expression of transient receptor potential vanilloid-1 (TRPV1) in urothelial cancers of human bladder: relation to clinicopathological and molecular parameters. Histopathology, 57: 744, 2010.

29. Walder, R. Y., Rasmussen, L. A., Rainier, J. D., Light, A. R., Wemmie, J. A., and Sluka, K. A.: ASIC1 and ASIC3 play different roles in the development of Hyperalgesia after inflammatory muscle injury. J Pain, 11: 210, 2010. 
Table 1

\begin{tabular}{|c|c|c|c|}
\hline & ASIC1a & ASIC2a & ASIC3 \\
\hline isolated urothelium $(n=4)$ & $25.3 \pm 0.82 *$ & $29.9 \pm 0.4 *$ & $20.4 \pm 0.79 *$ \\
\hline stroma $(n=4)$ & $21.48 \pm 0.52$ & $29.3 \pm 0.76 *$ & $19.12 \pm 0.43$ \\
\hline UE cultures $(n=3)$ & $21.87 \pm 0.42$ & $31.9 \pm 0.44 *$ & $23.4 \pm 0.75$ \\
\hline SM cultures $(n=3)$ & $21.5 \pm 0.49 *$ & $32.11 \pm 0.18 *$ & $24.5 \pm 0.19 *$ \\
\hline TEU-2 monolayer $(n=6)$ & $21.57 \pm 0.31 *$ & $31.36 \pm 0.15 *$ & $23.48 \pm 0.05 *$ \\
\hline $\begin{array}{l}\text { TEU-2 multilayer } \\
\text { (72h differentiation) }(n=6)\end{array}$ & $22.4 \pm 0.10 *$ & $28.4 \pm 0.32 *$ & $19.69 \pm 0.27 *$ \\
\hline
\end{tabular}

Table 1. Normalized expression values ( $\Delta \mathrm{Ct}$ values) of ASICs in human bladder, cultured UE and bladder SM cells and TEU-2 cell line.

Average Ct values detected in QPCR reactions of endogenous control (28S rRNA) were subtracted from the $\mathrm{Ct}$ values obtained during amplification of ASIC cDNA to obtain $\Delta \mathrm{Ct} \pm \mathrm{SEM}$. $\Delta \mathrm{Ct}$ values are inversely proportional to the amount of template, i.e. a higher $\Delta \mathrm{Ct}$ value indicates a lower amount of the target cDNA. Statistically significant differences in the expression levels of an individual ASIC compared to all the other studied ASICs in the same sample are indicated $(* \mathrm{p}<0.05)$. 


\section{FIGURE LEGENDS}

Figure 1. Purity evaluation of bladder urothelium, separated by dispase II treatment Urothelium was separated from the underlying stroma in samples of normal human bladder (n=4), and mRNA levels of UE and SM-specific markers determined by TaqMan QPCR. (A) The results were normalized to $18 \mathrm{~S}$ RNA and expressed as fold difference relative to the average value for the bladder samples. (B) End-point PCR amplification of 18S, SM22 and UP2 in representative samples: $\mathrm{BI}=$ bladder, $\mathrm{UE}=$ dispase-dissociated urothelium, $\mathrm{Str}=$ stroma.

Figure 2. Quantitative evaluation of mRNA levels of ASIC1a, -2a and -3 in human bladder layers and in urothelial and smooth muscle cell cultures

(A) Urothelium (UE) was separated from the underlying stroma in samples of normal human bladder $(\mathrm{n}=4)$, and mRNA levels of ASIC1a, $-2 \mathrm{a}$ and -3 were determined by SYBR QPCR using specific primer pairs and were normalized to $28 \mathrm{~S}$ rRNA. The data are expressed as fold difference relative to the average value for the stroma. Statistically significant differences between the bladder layers are indicated $(* \mathrm{p}<0.05)$.

(B) Primary cultures of bladder smooth muscle (SMC) and urothelium (UEC) (n=3 each) were analyzed for the presence and quantity of ASIC mRNA using QPCR. The results were normalized to 28S rRNA and expressed as fold difference relative to the average value for the smooth muscle culture.

Figure 3. Immunofluorescence detection of ASIC1 in human bladder

Ultrathin sections of the bladder dome obtained from 4 subjects were double labeled with anti-SM $\alpha$ actin monoclonal antibody (green) to localize the sub-urothelial muscle layer, and anti-ASIC1 polyclonal antibody (Red). Nuclei were stained with DAPI. Representative images of urothelium (top panel) and smooth muscle (bottom panel) are shown.

\section{Figure 4. TEU-2 up-regulate ASIC2a and ASIC3 during differentiation}

(A) TEU-2 cells were grown on glass coverslips and stained with anti-occludin antibody (Invitrogen). Nuclei were visualized with DAPI. Upper panel - monolayer cultures of undifferentiated TEU-2; lower panel: TEU-2 after $72 \mathrm{~h}$ in differentiation medium

(B) mRNA levels of ASIC1a, -2a and -3 were determined by QPCR in undifferentiated TEU-2 monolayers, and $24 \mathrm{~h}, 48 \mathrm{~h}$ and $72 \mathrm{~h}$ after inducing differentiation. The results were normalized to $28 \mathrm{~S}$ rRNA and expressed as fold difference relative to the average value for monolayer cultures. The graphs show an average of 3 experiments \pm SEM. Statistically significant differences with the undifferentiated cells are indicated $(* \mathrm{p}<0.05)$.

Figure 5. TEU-2 and human cultured urothelium cells express functional ASICs 
Proton-induced currents were measured by whole-cell voltage-clamp to $-60 \mathrm{mV}$ from undifferentiated TEU-2 cells and from cultured human urothelium cells. The measured urothelium cells were in contact with neighboring cells because they grow in clusters. (A) Representative traces from TEU-2 cells (left panel) or UE cells (right panel) which were subjected to a rapid pH change from $\mathrm{pH} 7.4$ to $\mathrm{pH} 6.0$ with or without $200 \mu \mathrm{M}$ amiloride for $5 \mathrm{~s}$ and $2.5 \mathrm{~s}$ respectively. For TEU-2 cells, the grey trace represents the amiloride-sensitive current component. (B) Representative traces of acid-evoked currents at different pH from a holding pH of 7.4 are shown for TEU-2 (left panel) and UE cells (right panel). (C) Peak current amplitudes were normalized for each cell to the current obtained at pH 6.0 and plotted as a function of the test $\mathrm{pH}$. Dashed curves represent the fit of the data points to the Hill equation, $n=6-10$. (D) The peak inward current inhibition by $200 \mu \mathrm{M}$ amiloride is shown for TEU-2 (hatched bars) and UE (filled bars) $n=8-10$.

Figure 6. TEU-2 cells preferentially express the TRPV1b isoform Samples of TEU-2 monolayer cultures $(n=5)$ and total bladder $(n=3)$ were analyzed for the mRNA levels of TRPV1 using the long isoform-specific primers, and the TRPV1+1b nondiscriminating primer pair. The results are shown as fold difference relative to the total TRPV1+1b amount $\pm \operatorname{SEM}(* * \mathbf{p}<\mathbf{0 . 0 0 5})$.

Figure 7. mRNA levels of ASIC1a, -2a, -3 and TRPV1 in BPS patients

(A) The mRNA levels of ASIC1a, $-2 \mathrm{a}$ and -3 in dome biopsies of 8 healthy controls, and 28 patients with BPS were determined by SYBR Green Real-time RT-PCR, normalized to 28S RNA and expressed relative to control averages. The graph shows the average for ASIC expression in bladder dome biopsies \pm SEM ( $n=8$ for control group; $n=28$ for BPS group). ASIC2a and ASIC3 mRNA levels are significantly $(* \mathrm{p}<0.05)$ up-regulated in BPS patients compared to controls. The mRNA levels of ASIC1a did not change between the two groups.

(B) mRNA levels of TRPV1 were determined by TaqMan QPCR using the TRPV1 $+1 \mathrm{~b}$ nondiscriminating primer pair. TRPV1 is significantly $\left({ }^{*} \mathrm{p}<0.05\right)$ down-regulated in BPS patients $(\mathrm{n}=28)$ compared to controls $(\mathrm{n}=8)$. 
A

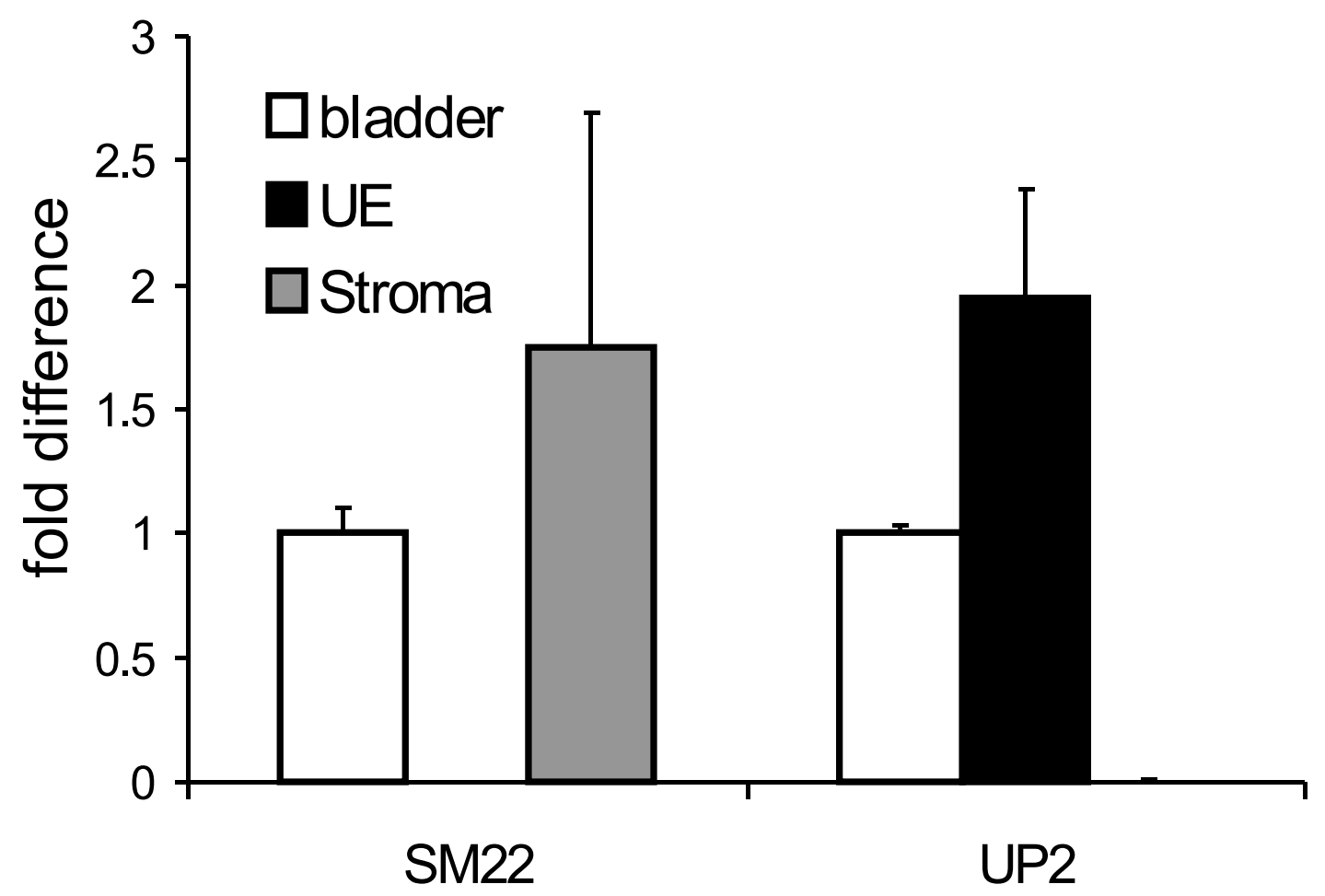

BI UE Str BI UE Str BI UE Str

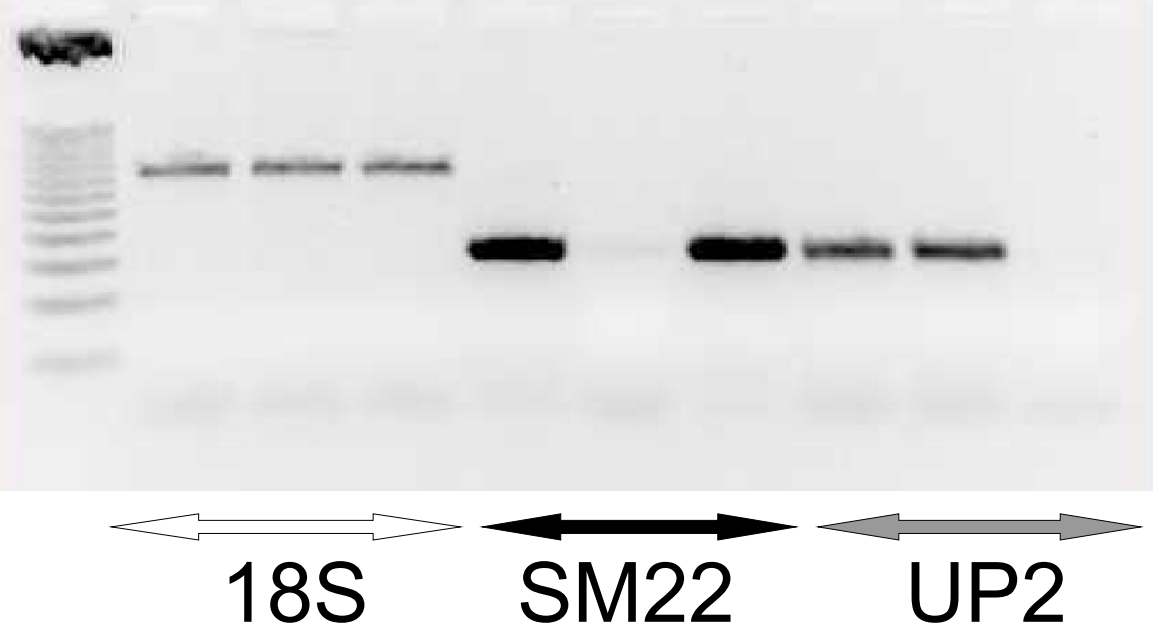

Fig. 1 
A

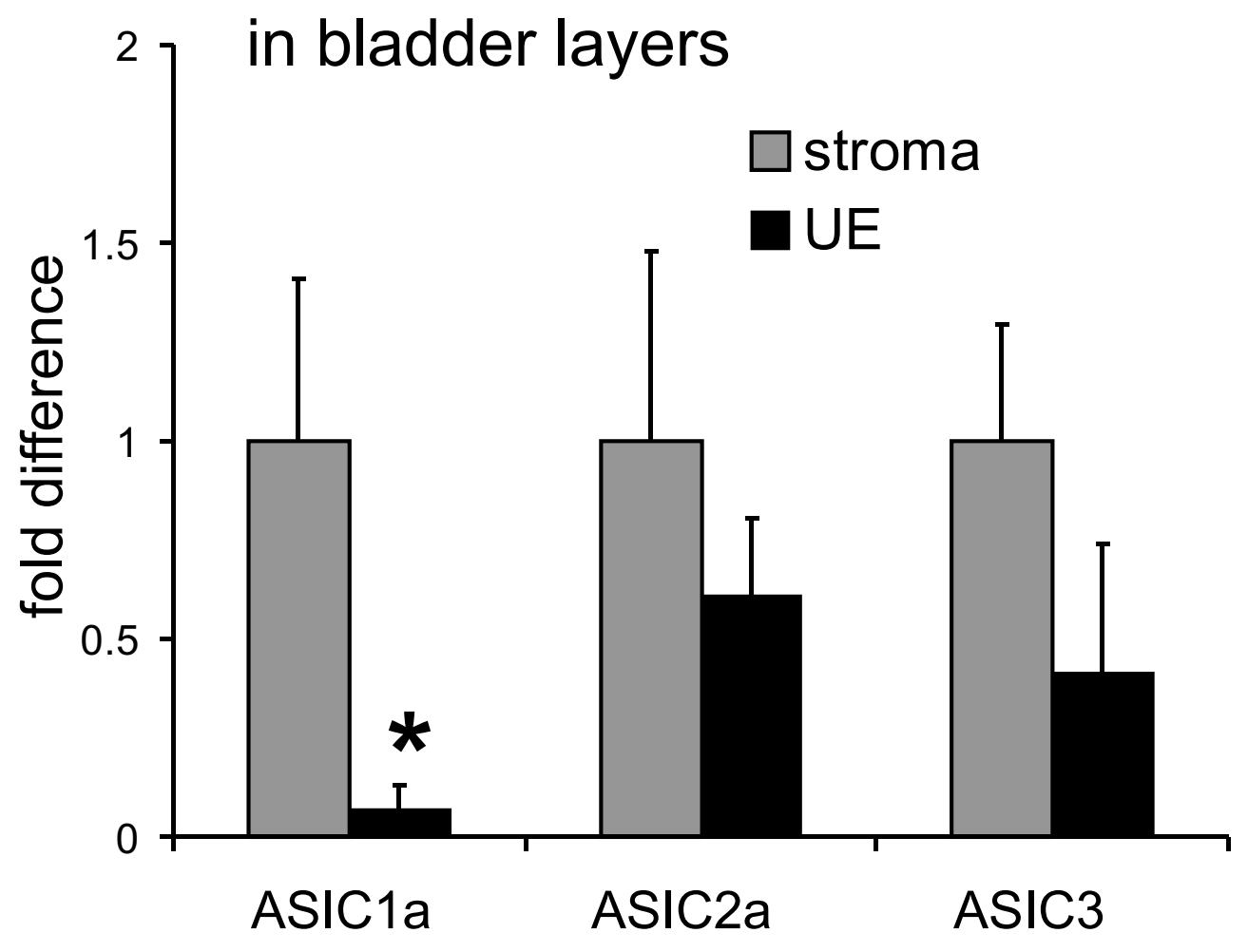

B

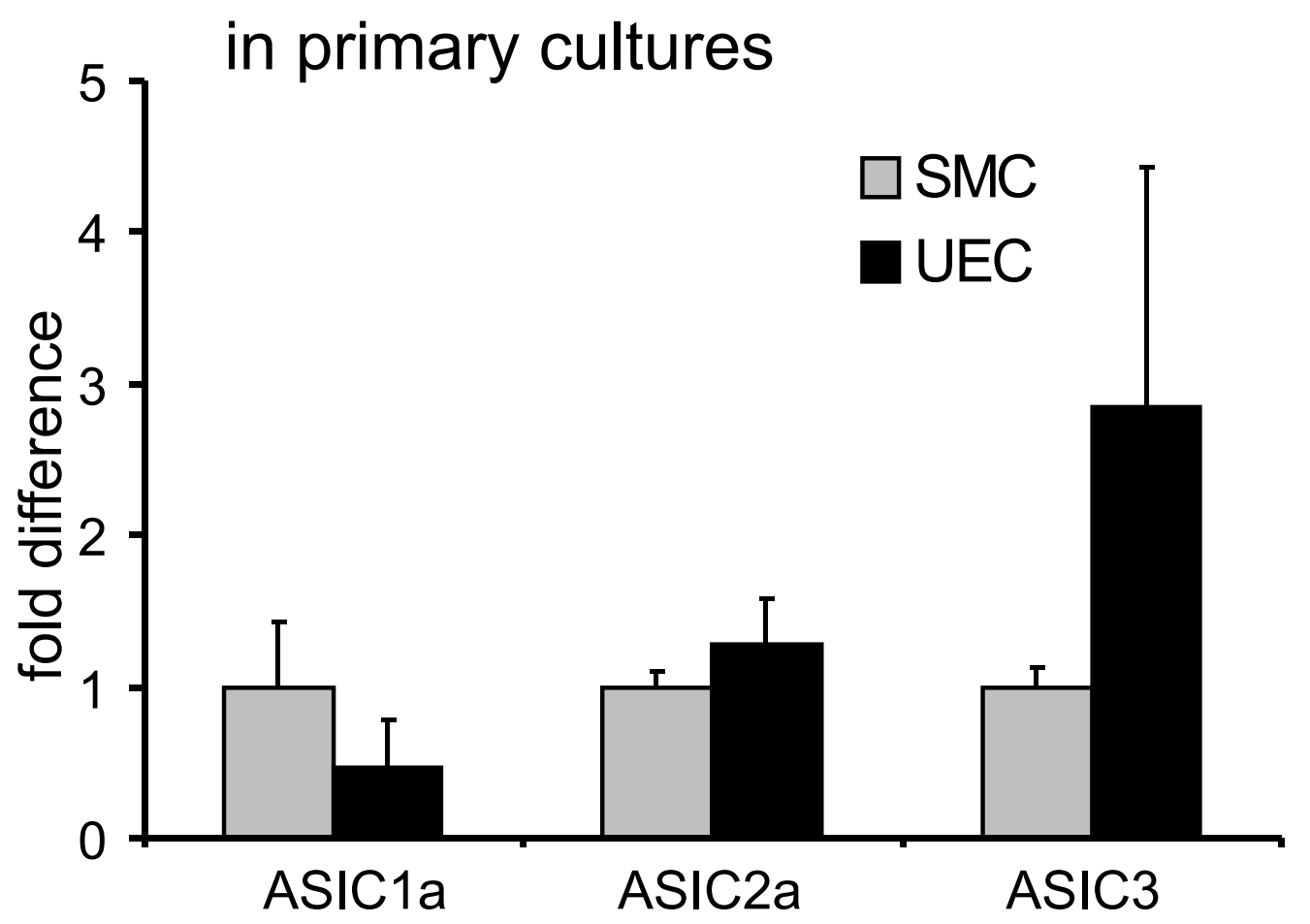

Fig. 2 


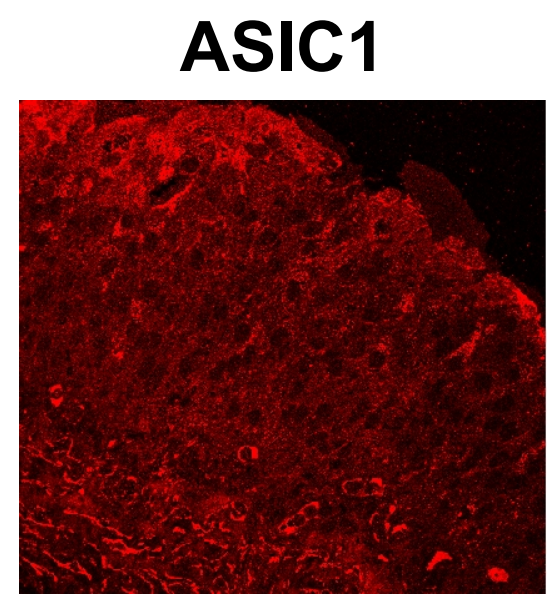

DAPI

merge
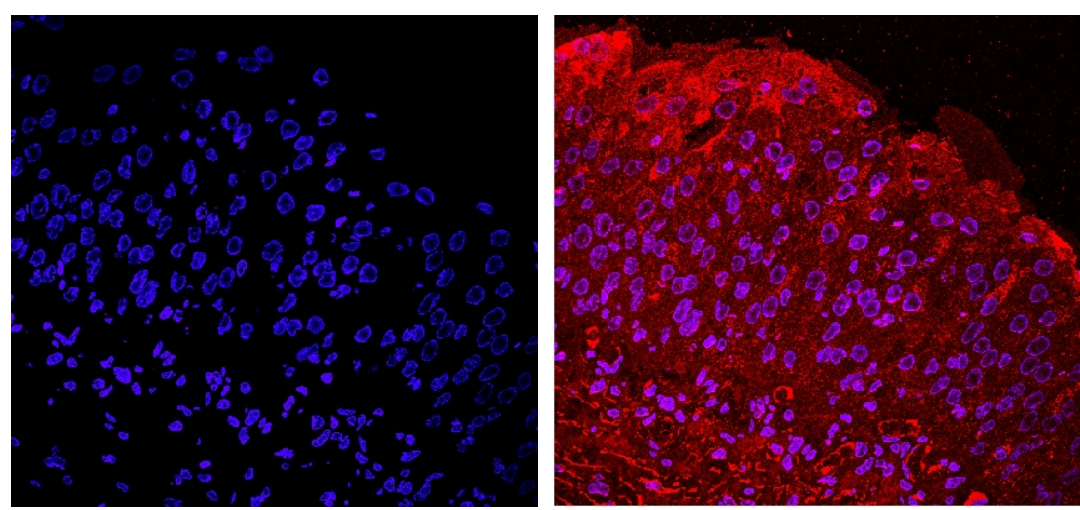

\section{urothelium}
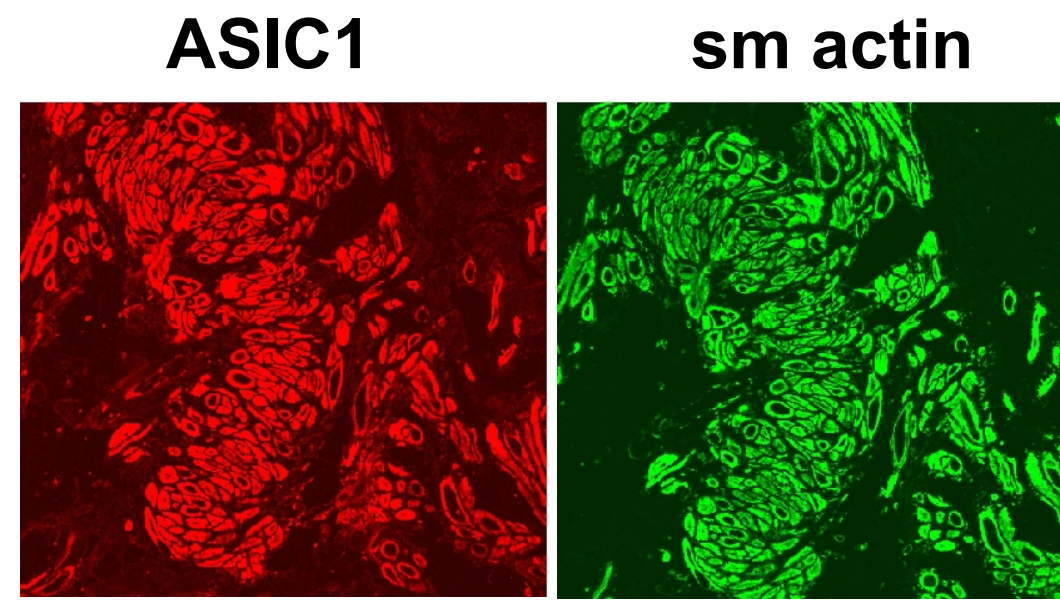

merge

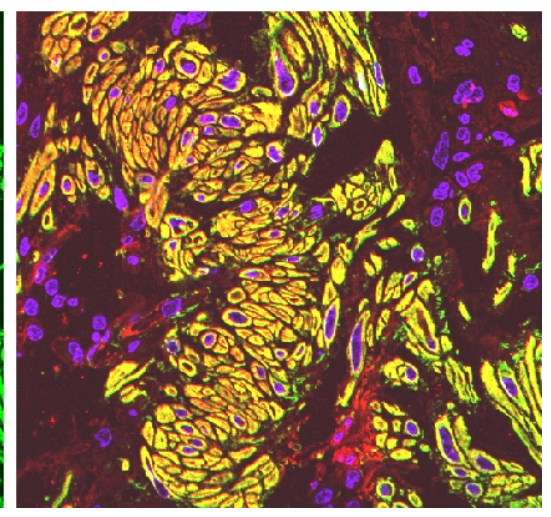

smooth muscle

Fig. 3 
A

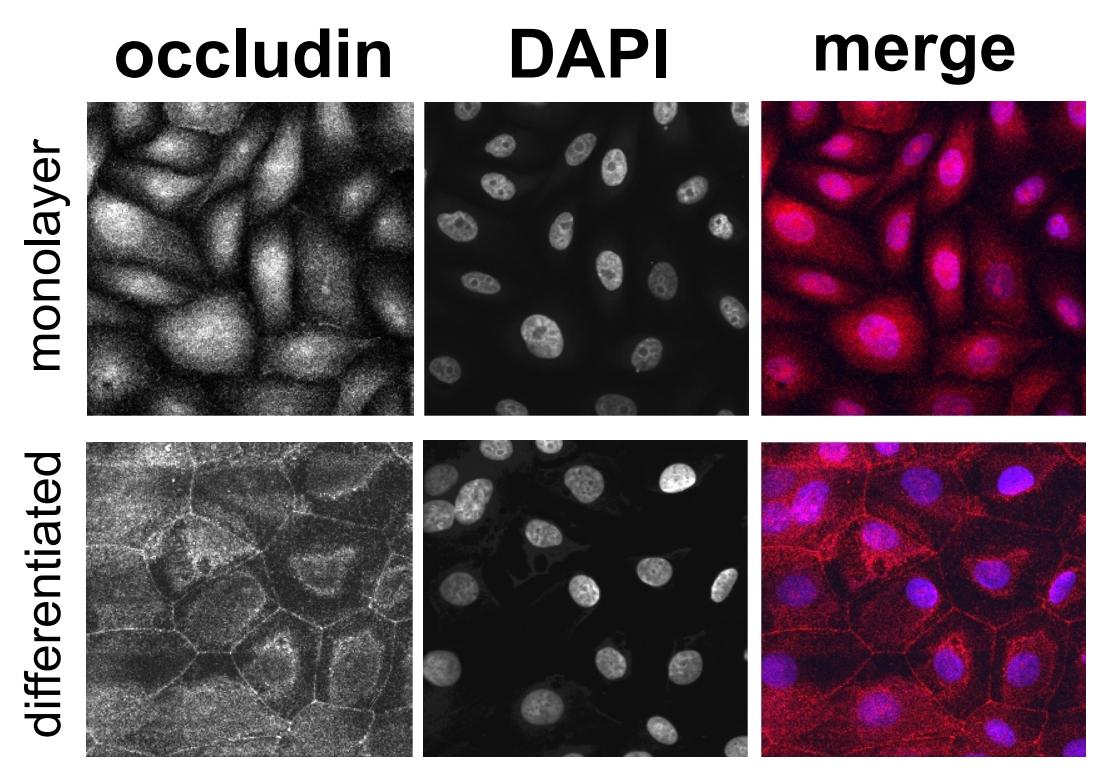

B

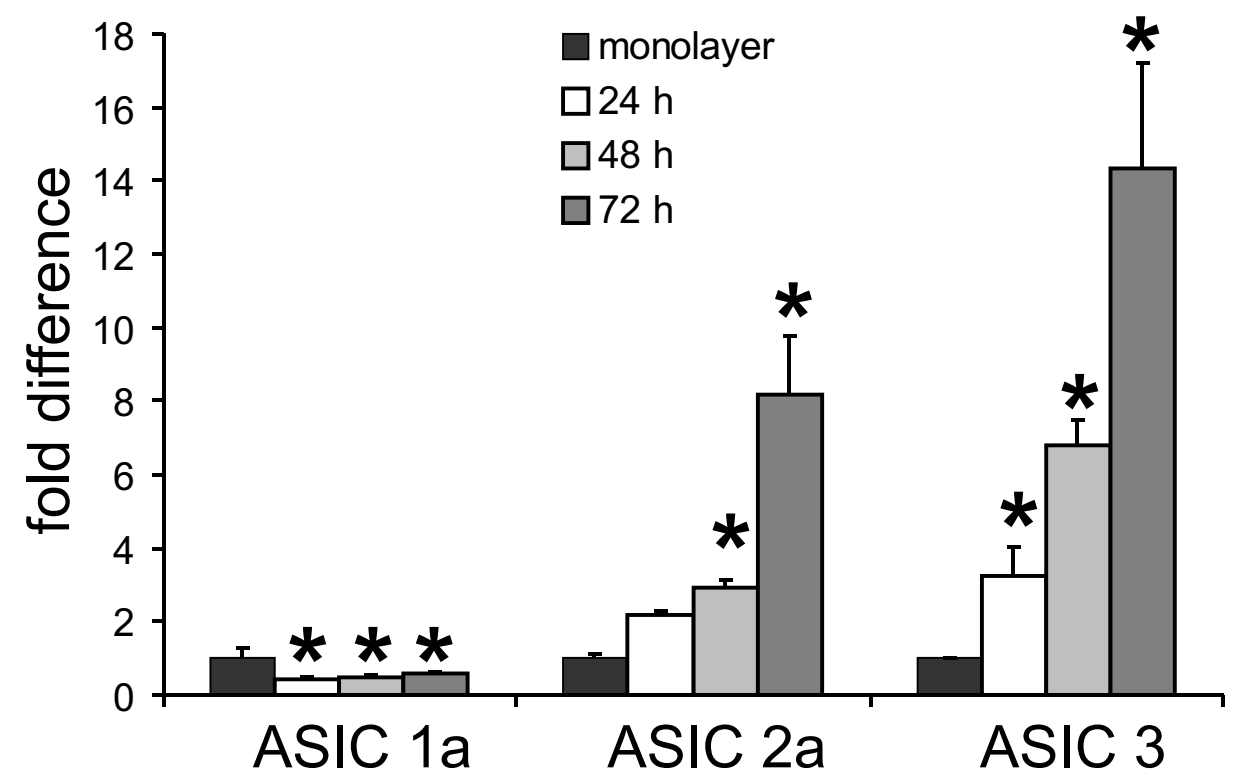

Fig. 4 
A
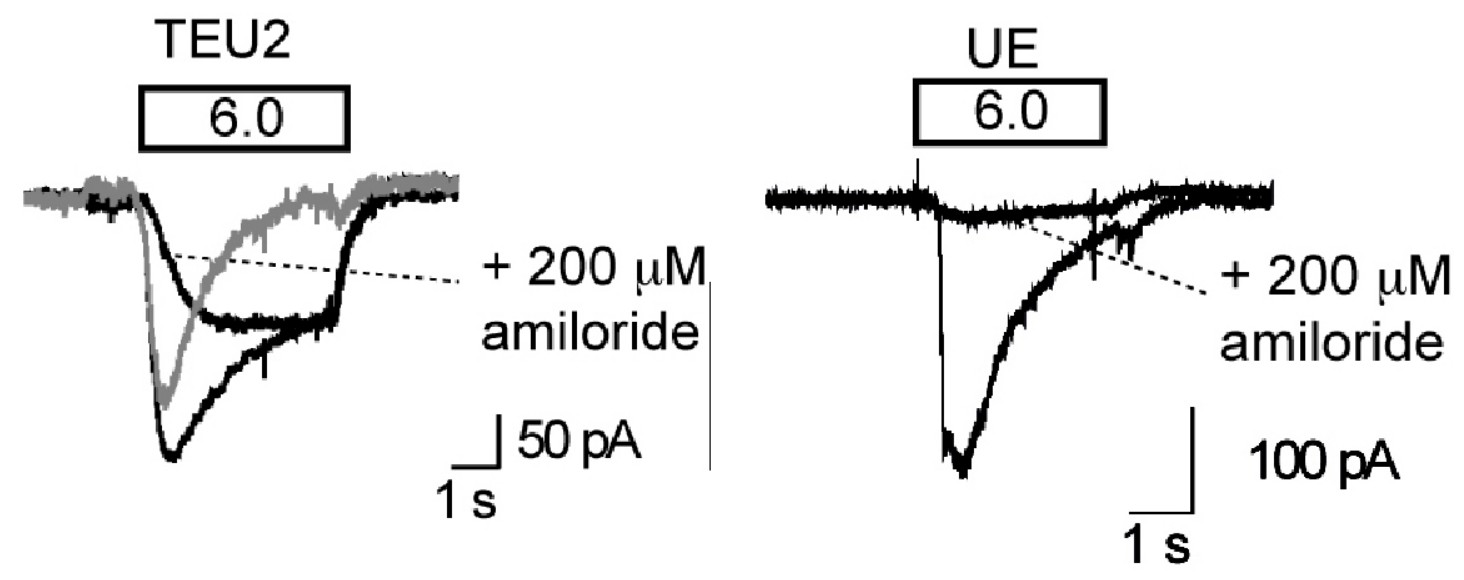

B
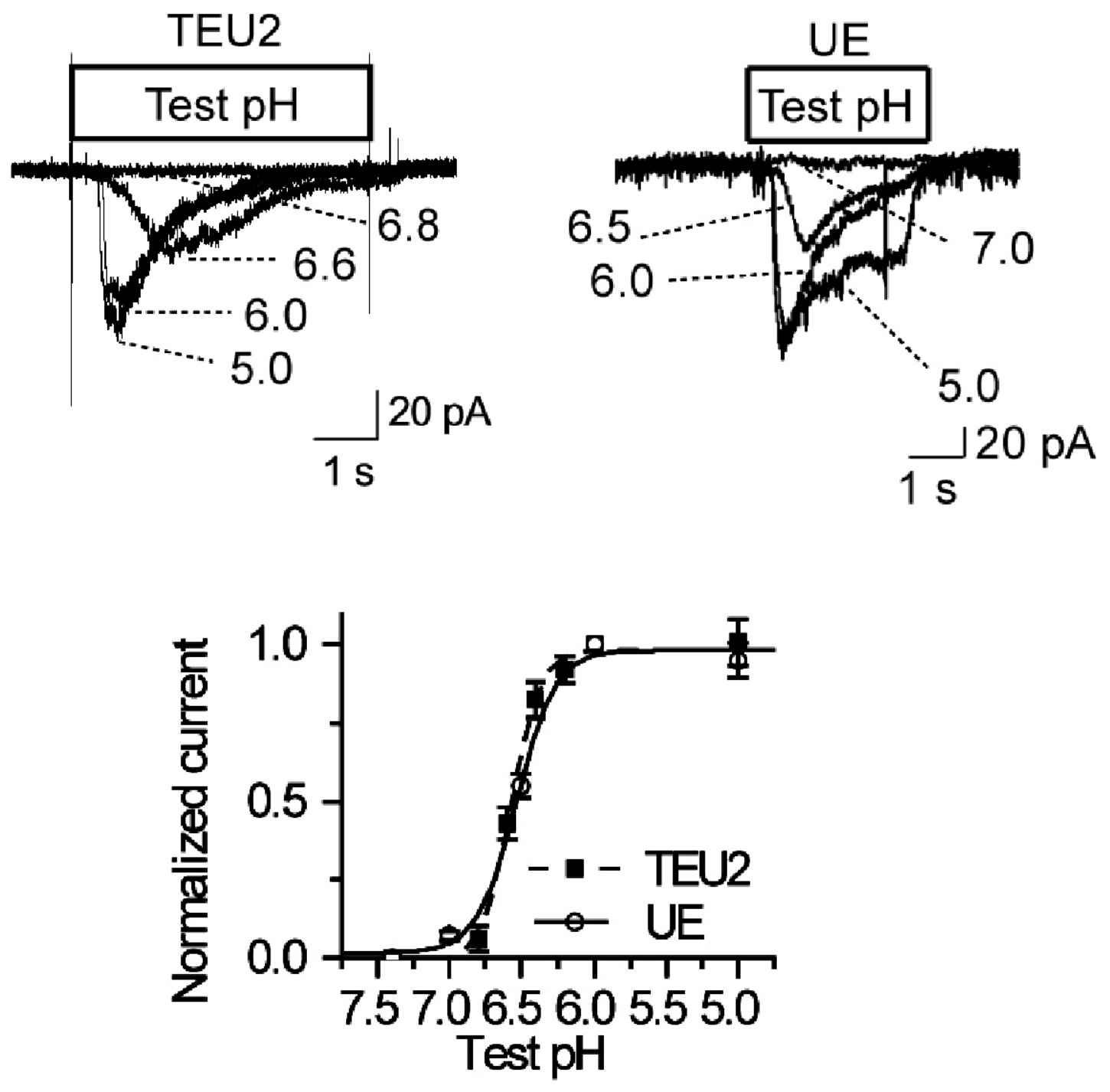

D

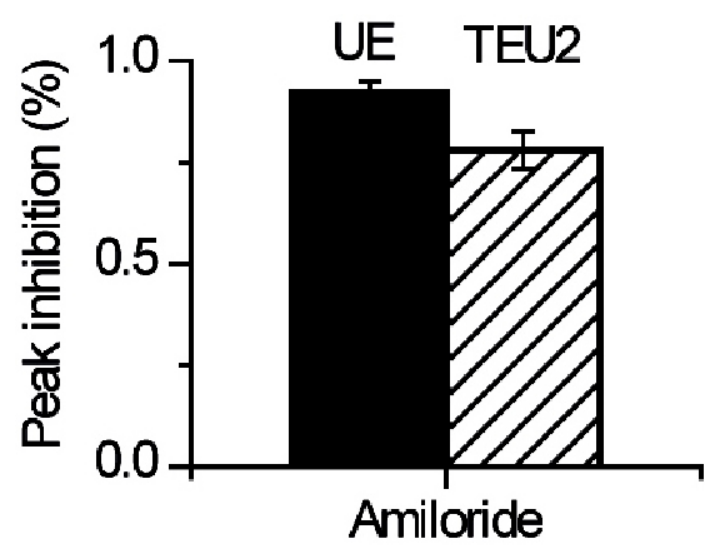

Fig. 5 


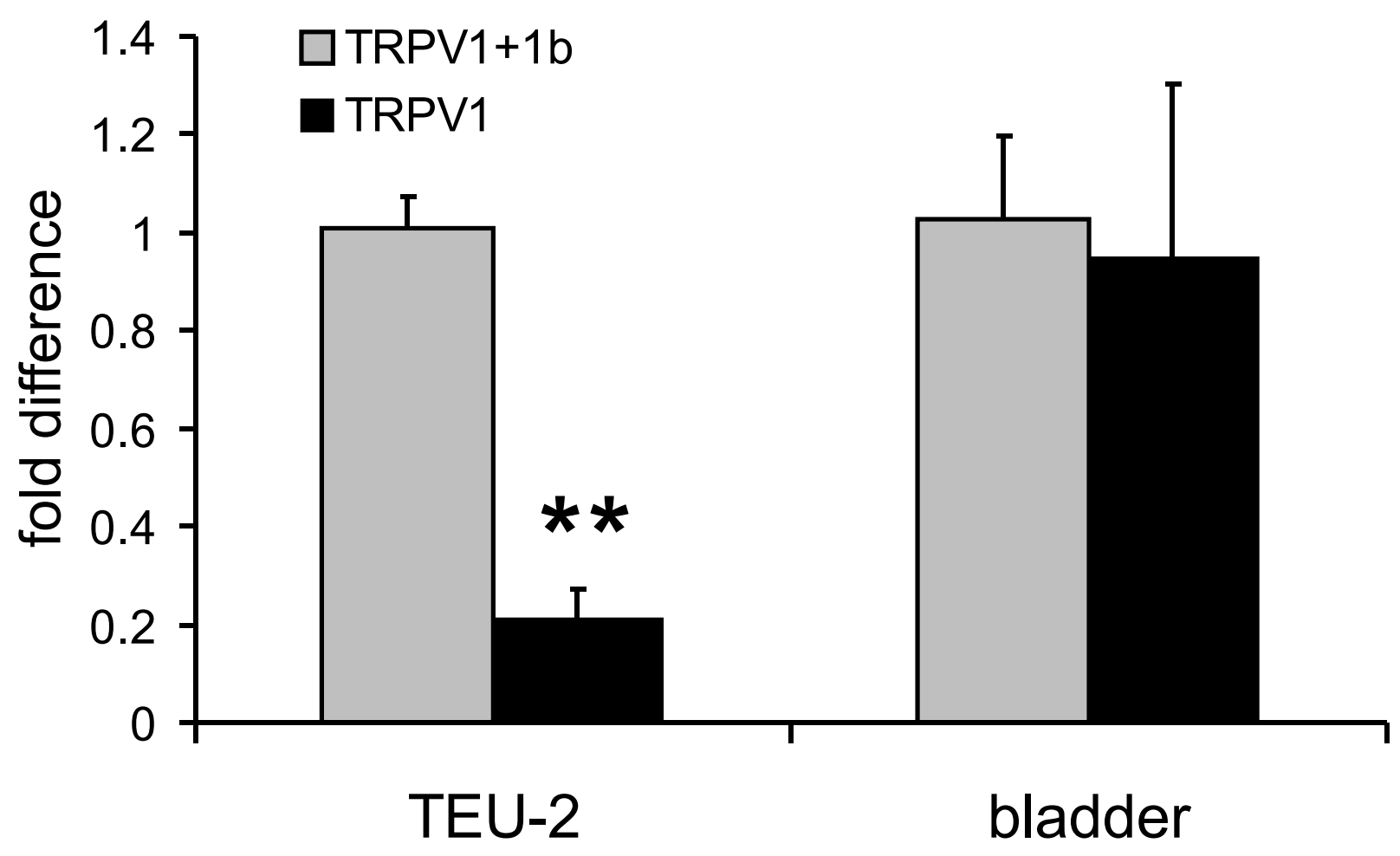

Fig. 6 
A

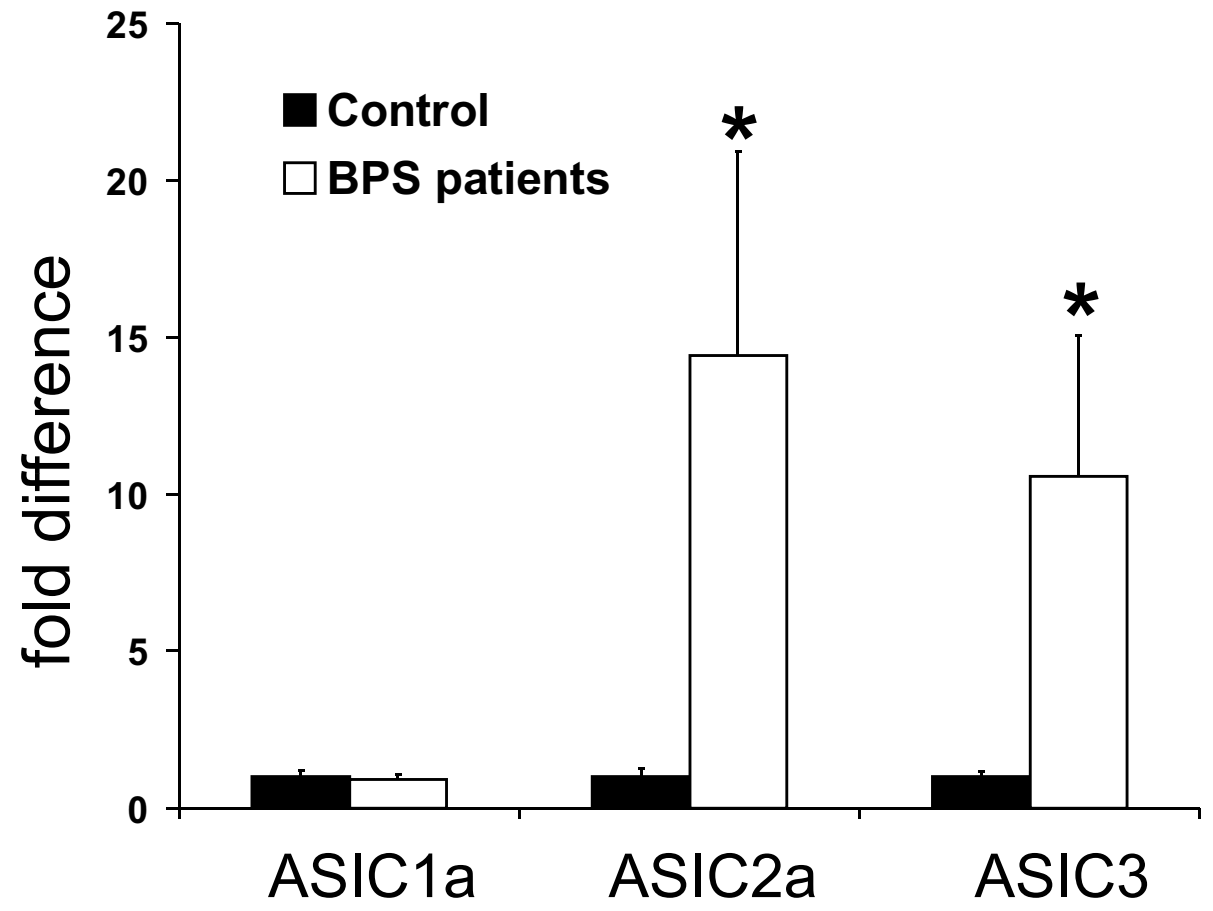

B

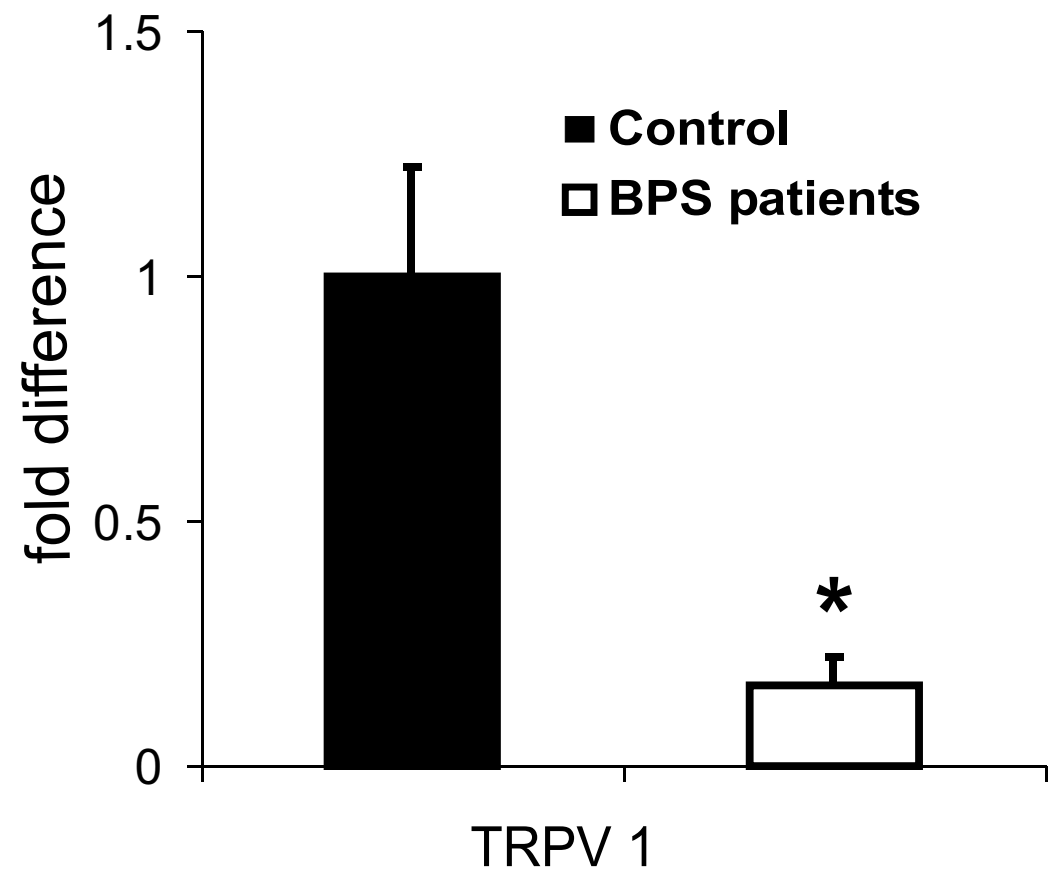

Fig. 7 